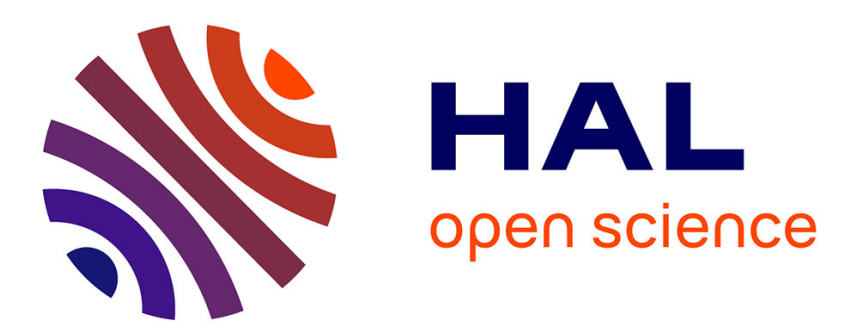

\title{
The diagnostic and control system for the converted MP-Tandem at Munich
}

\author{
H. Jakob, L. Rohrer, H. Schnitter
}

\section{To cite this version:}

H. Jakob, L. Rohrer, H. Schnitter. The diagnostic and control system for the converted MP-Tandem at Munich. Revue de Physique Appliquée, 1977, 12 (10), pp.1399-1402. 10.1051/rphysap:0197700120100139900 . jpa-00244332

\section{HAL Id: jpa-00244332 https://hal.science/jpa-00244332}

Submitted on 1 Jan 1977

HAL is a multi-disciplinary open access archive for the deposit and dissemination of scientific research documents, whether they are published or not. The documents may come from teaching and research institutions in France or abroad, or from public or private research centers.
L'archive ouverte pluridisciplinaire HAL, est destinée au dépôt et à la diffusion de documents scientifiques de niveau recherche, publiés ou non, émanant des établissements d'enseignement et de recherche français ou étrangers, des laboratoires publics ou privés. 


\title{
THE DIAGNOSTIC AND CONTROL SYSTEM FOR THE CONVERTED MP-TANDEM AT MUNICH
}

\author{
H. JAKOB, L. ROHRER and H. SCHNITTER \\ Beschleunigerlaboratorium der Universität \\ und der Technischen Universität München, 8046 Garching, Hochschulgelände, R.F.A.
}

\begin{abstract}
Résumé. - Le système de diagnostic et de contrôle du Tandem MP de Munich est basé sur deux faisceaux de guide-lumière acryliques allant dans la structure de la colonne des extrémités du tank vers les sections neutres et vers le terminal. Ces guide-lumière transmettent tous les signaux de contrôle pour les lentilles, les steerers, les strippers à feuille et les diaphragmes variables. Ils transmettent également les lectures pour les mesures d'intensité de courant de charges, de courant de colonne, de courant d'ionisation, de courant de pompe et de tension, et la fréquence d'alternateur. On présente des détails de la conception mécanique et électronique.

Avant que le système ait été installé, les composantes ont subi différents essais de haute tension et de radiation. Le système a été installé en juin 76 . L'expérience de fonctionnement et les résultats des essais sont reportés.
\end{abstract}

\begin{abstract}
The diagnostic and control system for the Munich MP-Tandem is based on two bundles of acrylic light pipes running in the column structure from both ends of the tank to the dead sections and to the terminal. These light guides transmit all control signals for lenses, beam steerers, foil strippers and variable apertures as well as the readings of beam currents, charging currents, column currents, ionization currents, pump currents and voltages, and alternator frequencies. Details of the mechanical and electronic design are presented.

Before the system has been installed, parts of it have passed various high voltage and radiation tests. It has gone in operation in june 1976. Operating experiences and test results are reported.
\end{abstract}

1. Introduction. - For the converted MP-Tandem at Munich with its relatively complicated beam optics system, involving several lenses and steerers within the pressure tank, a control system and a rather extensive diagnostic system has been developed.

To meet the requirement for a great number of channels an optical data transmission system is best suited. A large number of single lines has been preferred to a system in multiplex operation [1] for several reasons: data links are needed not only to the terminal but also to each dead section. The operation in multiplex mode is limited to only one of the locations mentioned if not several multiplex systems are used. The operating mode of single lines can be easily adapted to the required accuracy and transmission speed. Signal lines between different crates in the accelerator are not needed, so the problems of surge protection of these lines do not arise. If units of a device carry different potentials, e.g. if a steerer voltage has to be superimposed to a quadrupole lens voltage, the units can be separately controlled and monitored by single light links. Finally, if a single transmission line fails, the accelerator can be operated in most cases without severe difficulties.

2. The Light Pipes. - A sufficient number of optical data links, consisting of lenses and mirrors, can hardly be placed in the available space; therefore light guides have been installed.

Coated glass fibre light pipes are not suited for this purpose for two reasons: Firstly, their dielectric strength is poor, and they can be blasted by a spark because of the lubricant and moisture between the single fibres. Secondly, glass would be coloured brown by the gamma radiation near the accelerating tube. Therefore a lucite light guide with the trade name Lemosa Lumafil is used. It is a single acrylic fibre, coated with an other acrylic material with a lower refraction index, so that total reflexion occurs.

Before the final decision on the light pipes was made several tests were performed. A high voltage test showed that the light guide does not break down at a gradient of more than $2.2 \mathrm{MV} / \mathrm{m}$. During a radiation test a light pipe (together with electronic equipment) was exposed to a gamma dosis of $1000 \mathrm{rad}$. No change in the light pipes or the electronic equipment was noticed after this irradiation. Several samples of material were exposed to $86 \times 10^{3} \mathrm{rad}$. During this test a glass sample was coloured brown, but the lucite light pipe remained operable. The transmission of the light guide as a function of the wavelength has been measured. As shown in figure 1, the light guide is suited for a wavelength between 600 and $800 \mathrm{~nm}$, corresponding to red light. 


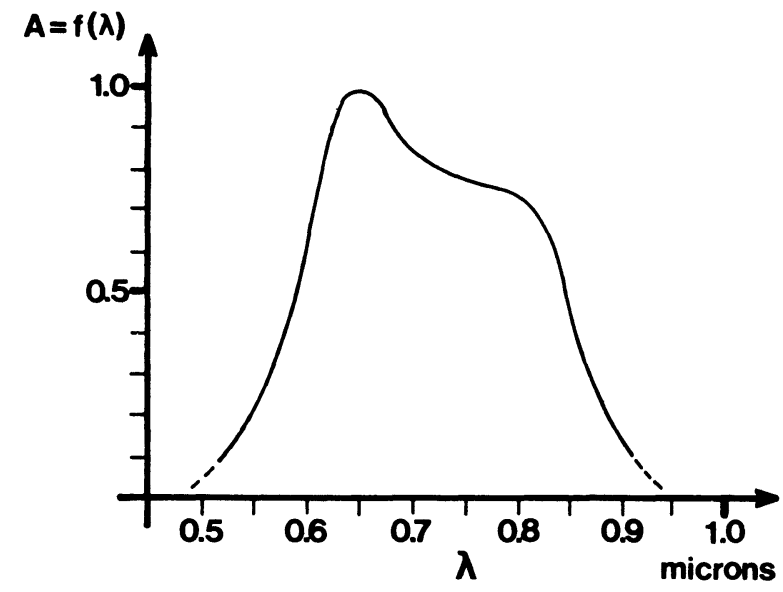

FIG. 1. - Transmission of the light guide.

The best way of mounting light pipes in the column of the accelerator has been explored during high voltage tests of the machine with no tubes being installed. A bundle of light pipes in a lucite tube was damaged by sparks. Light pipes directly mounted to the column structure - this was tried because a better grading was expected - were also damaged. Finally the fibres were suspended between two dead sections without intermediate support and twisted so that they touch each other, and major potential differences cannot occur. The mounting hardware (Fig. 2) is designed to hold the light pipes mechanically, to connect them electrically to the dead sections (by means of an indium wire), and to form the electrical field so that the light pipes are screened at the feedthrough. With a bundle of light pipes being installed in this way a terminal voltage as high as $16 \mathrm{MV}$ could be reached, and the light pipes have not been damaged in spite of many tank sparks during this test period.

In the terminal and in the dead sections the light guides are partly running free, partly they are mounted in a lucite tubing (to protect them against damage

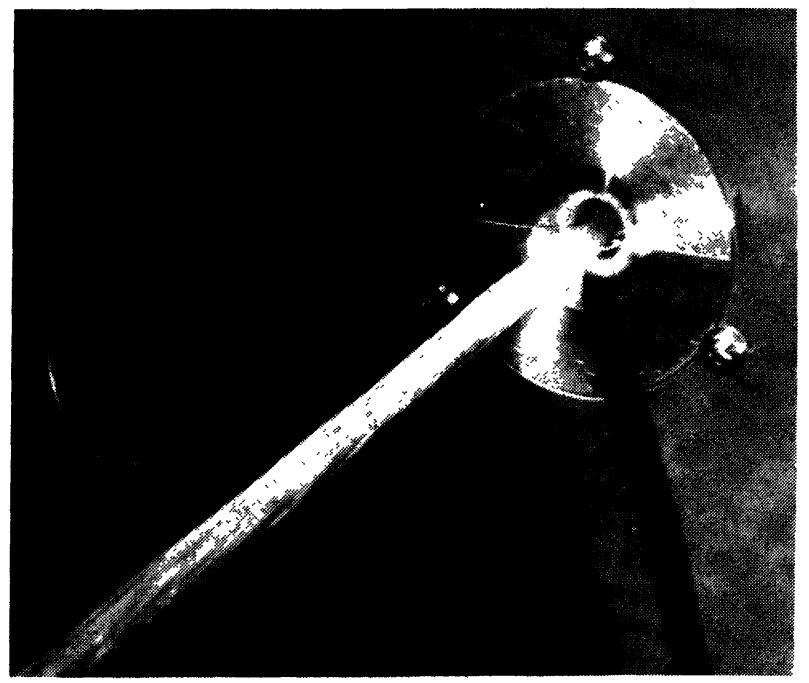

FIG. 2. - A bundle of light pipes entering a dead section. during maintenance periods). Polyamide tubes have not proved good, the surface of the light pipes had become faint, presumably caused by the softener contained in this material. No light pipe failed so far, but it cannot be excluded that fibres could be damaged in a longer time by the softener.

The transmitters and receivers on ground potential are located outside the tank. The tank feedthroughs for the light pipes (Fig. 3) are made of a bolt which is drilled through. The fibre is glued into this hole, and the bolt is sealed in a tank flange with a little o-ring.

The ends of the light pipes are also glued in such a bolt and mechanically polished. A polishing fluid offered by the light pipe manufacturer, making a thin film on the surface, is not suitable. The film does not adhere very reliably, and the transmission becomes worse with time. Polished ends of fibres can be coupled together mechanically, in this way broken light pipes can be repaired.

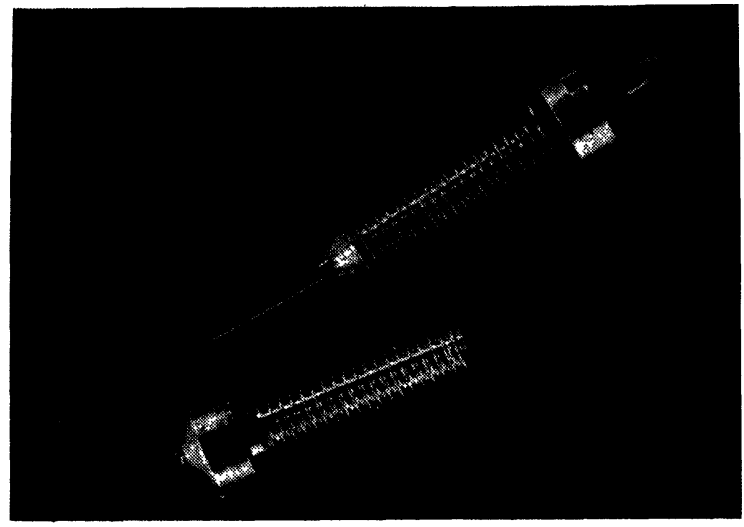

FIG. 3. - Tank-feedthrough and end-piece of a light pipe.

3. Transmitters and Receivers. - The transmitter consists of a light emitting diode (5 082-4 656, Hewlett-Packard) matching to the transmission curve of the light pipe, and a driver circuit which delivers current pulses of $0.5 \mathrm{~A}$ amplitude and $1 . .22 \mu$ s duration to this LED. The LED is coupled to the light guide by an adjustable device consisting of excentric rings as shown in figure 4 . This is necessary because

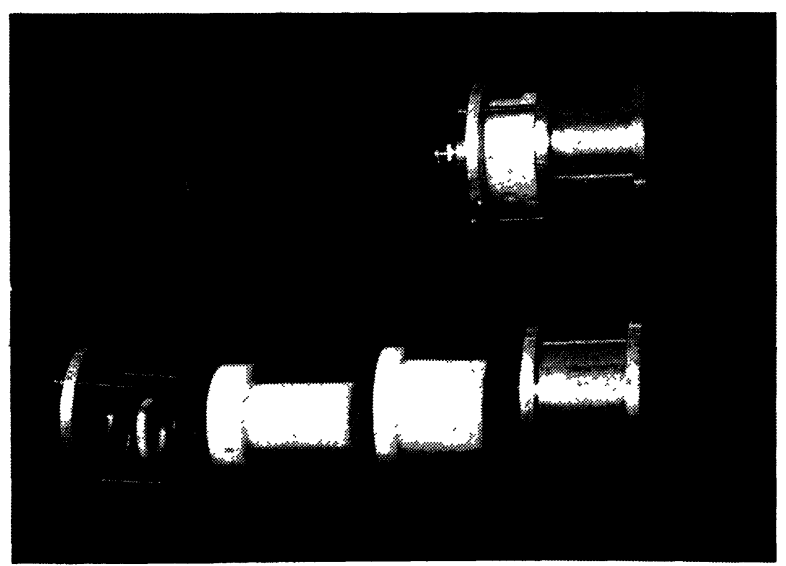

FIG. 4. - Adjustable mounting hardware for photodiodes and LED's. 
the active elements of the diodes are not very well centered in their capsules.

As a receiver a photodiode (MD2, Monsato), mounted in the same way as the LED, is used. If the light pipe has a length of about $20 \mathrm{~m}$ one obtains pulses of $300 \ldots 500 \mathrm{nA}$ which can easily be amplified to a normal logic level.

To transmit analog signals in most cases frequency modulation is used. Only for quadrupole lenses and steerer controls pulse phase modulation is preferred, because one can transmit two or three signals by a single light pipe. A pulse diagram is shown in figure 5. A reference pulse, marked as a double pulse, synchronises a saw-tooth generator in the demodulator unit, so that zero-crossing occurs at the marked position. The other pulses contain the signal information as distances from the zero marks. A corresponding voltage is detected with a sample and hold gate which samples the saw-tooth in the moment of the pulse. Channel $\mathrm{O}$ is sampled by another sample and hold gate, its output is used to control the saw-tooth frequency.

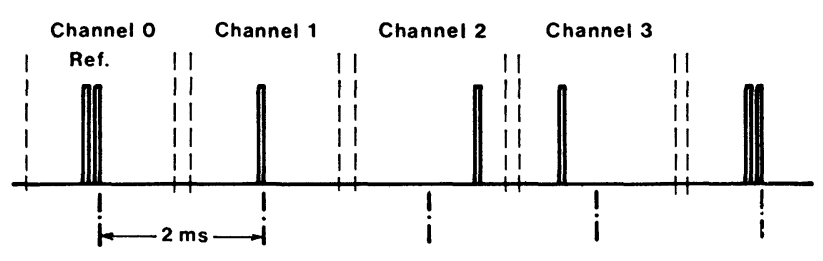

Fig. 5. - Pulse phase modulated signal.

4. Devices in the Terminal and in the Dead Sections. - The most simple device in the terminal is the alternator monitor. From each alternator the voltage is fed to a neon lamp which is used as a transmitter instead of the LED being used in other devices. By this unit the operation of the terminal alternators is monitored and the frequency is measured. The frequency information is useful for detecting slippage of the Pelletron chains.

Beam currents in the terminal and in each dead section, charging currents and column currents in the terminal and ionization currents at the terminal are monitored by a battery operated device, which is described in detail in contribution D6 of these proceedings.

For currents of ion getter pumps in the dead sections and in the terminal another sender has been developed, which is less accurate but suited for currents up to $1 \mathrm{~A}$. It consists of a pair of diodes to get a logarithmic signal and another pair of diodes to compensate for the temperature cœefficient of the logdiodes. The logarithmic signal is converted into a frequency signal and transmitted by the LED. The pump voltages are monitored by a very simple voltage to frequency converter consisting of an RC-network and a neon lamp which is used as a light emitter.

The control systems of the two foil strippers and the two variable apertures in the terminal are described in the contributions D7 and $\mathrm{H} 7$ of these proceedings.

The electrostatic quadrupole lenses and steerers in the terminal and in the low energy mid dead section are controlled by light links operated in pulse phase modulation, as mentioned before. The high voltage power supplies are made of power packs containing a transformer and a rectifier circuit with a high voltage capacitor. The output voltage is stabilized by a triac circuit with phase control.

\section{Wiring and Screening in the Terminal and in the}

Dead Sections. - Under surge conditions electromagnetic fields penetrate into normally field-free regions of the accelerator. Inside the terminal surge voltages can reach several hundred kilovolts. All electronic equipment must be carefully screened to prevent surge damage.

Most of the electronic units in the dead sections and in the terminal are double screened by boxes made of 2-3 mm aluminium sheet. Figure 6 shows the terminal with a lens power supply and a power distribution box. Only the current monitors and the stripper control units have a single screen. The current monitors have been in troublefree operation for all the time, but damages occurred to the stripper control units, particularly to one which is near to another grounded part of the terminal construction. Sparks from there seem to cause the destruction.

All wiring from the alternators to the power distribution boxes and from there to the electronic units runs in copper tubes or bellows. Extremely high surges cannot occur on these lines because all units connected to them are screened. Nevertheless a silicon insulated wire is used, and the input of each unit is provided with a filter consisting of an induction coil, a capacitor and a surge arrestor or a VDR.

Wires which are connected to an unscreened point carry very high surge voltages, so that screening is neither practicable nor useful. If such an unscreened wire is connected to electronic equipment one has to insert an extremely good surge filter. Fortunately the currents on these lines are very low, and one can use high valued resistors together with spark gaps and surge arrestors.

6. Control Section. - The transmitter and receiver units are connected by pulse cables to the control room, where the modulators and demodulators together with the controls and meters are installed.

All lens controls have inputs for a master control voltage which is proportional to the ion energy for electrostatic lenses and proportional to the mass energy product for all magnetic lenses (in the post accelerator beam handling system). The information on the energy is derived from the extraction voltage, the pre-acceleration voltage, and the terminal voltage. The master voltage for the electromagnetic lenses is 


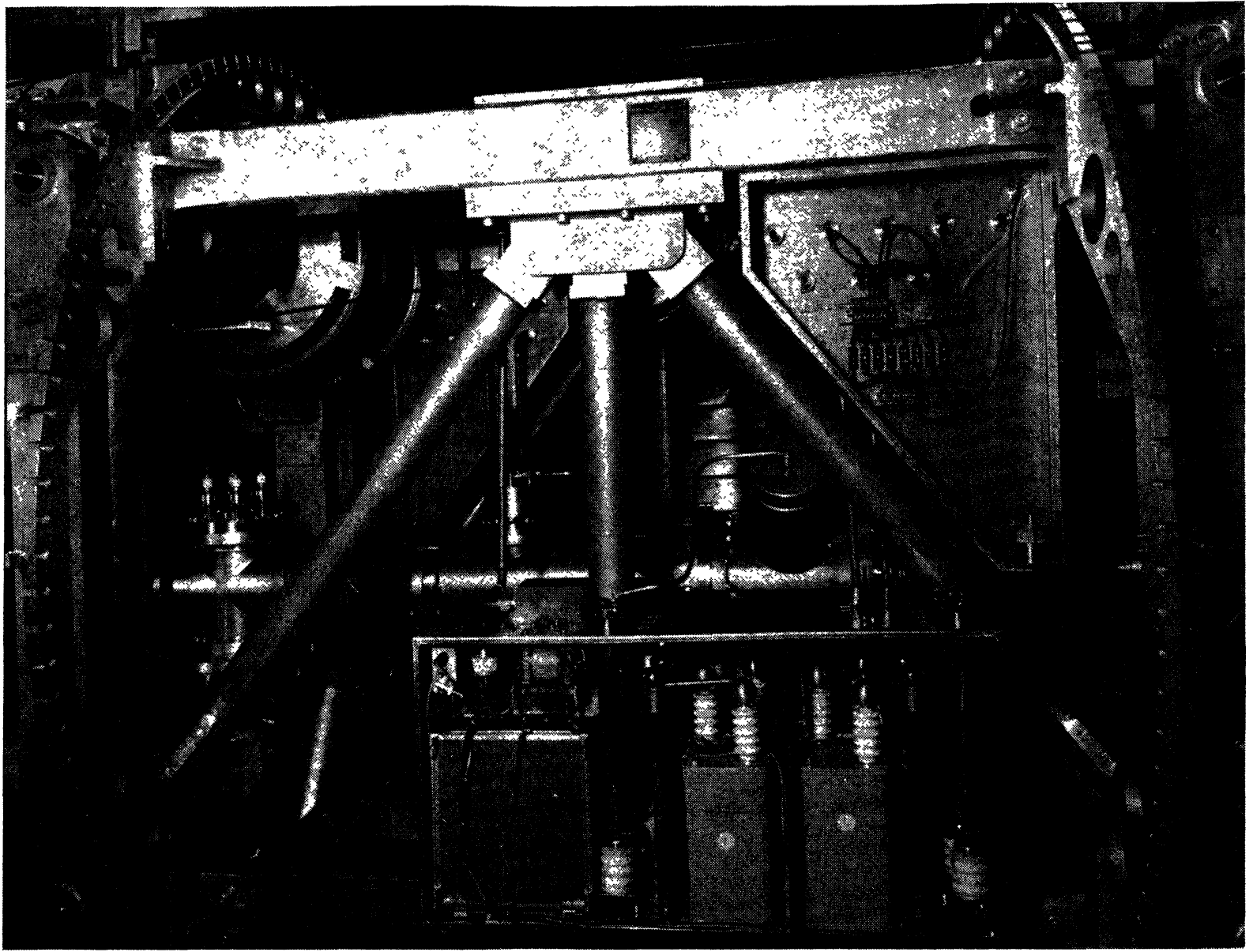

FIG. 6. - Terminal with a power distribution box and a lens power supply.

taken from the analysing magnet current. Using this master system one does not need to change the potsettings if the beam energy is changed.

Another feature of the quadrupole lens controls is that the knobs do not directly control the singlets of the lens, but one of them controls the field strength of all elements, the other one controls the difference between the strengths of the converging and the diverging singlets over a range of $\pm 10 \%$ of the actual value. With these control knobs for focus and astigmatism the beam is much easier to optimize than with controls of the singlets.

For the steerers an automatic control is provided, but not yet in operation in the acceleration section. (A similar system is in operation in the beam transport system.)

Each steerer is followed by a pair of slits or a divided aperture. The currents of these slits or apertures are logarithmically amplified and so a signal corresponding to the beam position is available. The signal can be fed into the steerer power supply, and so an automatic slit tracking of the beam can be achieved.

All control units are prepared to be connected to a computer system consisting of a PDP11-34, a graphic display unit (Afigraph) and CAMAC interface. The software is under development, and the first units will be connected in the next future. In the first stage of development accelerator supervision and extensive data analysis shall be provided. In a later stage the computer system shall be used to control parts of the machine.

7. Conclusion. - The monitoring and control system of the Munich MP tandem shows that, in general, electronic equipment can be used in a tandem accelerator with good results. The extensive use of the information displayed at the control desk facilitates a quick set up of the machine.

The experience with electronic equipment in the accelerator tank was that a few elements failed initially, for example an oil-filled power pack and a high voltage rectifier with small leaks were damaged by evacuating and pressurizing the tank. At other points surge damage occurred, and screening or filtering had to be improved. Many other devices have been operated without any failure up to now. One can conclude that, if a system is once in operation, and its protection is sufficient, it is a reliabe instrument.

\section{References}

[1] Horrabin C. W., Johnstone W. T. and Spurling K., DL/NSF'R/13, Daresbury (1975) 